\title{
Música de tecla en la España del siglo XVIII: \\ Domenico Scarlatti y el padre Antonio Soler
}

Paulino Capdepón Verdú

Universidad de Castilla-La Mancha

CES.XVIII, núm. 21 (2011), págs. 7-34. 
Resumen: El presente artículo se centra en la música española del siglo XVIII, que vive una de las etapas más brillantes de su historia. A ello contribuyó sin duda el esplendor logrado por la música de teclado, que alcanzó un extraordinario grado de desarrollo desde la llegada a España del compositor napolitano Domenico Scarlatti (1685-1757), maestro de clave de la reina de España Bárbara de Braganza. Scarlatti ejerció una influencia decisiva en la implantación del género sonata monotemática en un solo tiempo y en la introducción del estilo galante. Precisamente fue uno de los alumnos predilectos de Scarlatti, el padre Antonio Soler (1729-1783), el continuador de la obra scarlattiana en el ámbito de la sonata de tecla. Maestro de clave del infante don Gabriel y maestro de capillaorganista del monasterio real de El Escorial, su proximidad a la corte permitió al monje catalán conocer las principales novedades musicales propiciadas por la estancia en España de compositores italianos como el propio Scarlatti o Boccherini. Sin embargo, Soler supo evolucionar y otorgar su propio estilo a su producción para teclado: en la última etapa de su producción artística incorporó varios movimientos a sus sonatas, lo que sitúa al compositor español en la órbita de Haydn y Mozart. En este artículo, después de una introducción sobre la música española del siglo XVIII en general y de la música de teclado en particular, se estudian las trayectorias vitales de ambos compositores, así como sus respectivas aportaciones al ámbito de la sonata de tecla, que constituyen una de las cimas artísticas de la música española del siglo XVIII.

Palabras clave: Siglo XviII. Tecla. Estilo galante. Sonata. Scarlatti. Soler. Corte de Madrid. Monasterio de El Escorial. 


\section{Introducción: panorama musical español del siglo XVIII}

Al igual que ocurre en el ámbito del pensamiento, se observa en la música española del siglo XVIII una enconada lucha entre tradicionalistas y reformistas, defendiendo cada bando la práctica antigua frente a la moderna. Así pues, al igual que ocurriera en el siglo anterior, el Setecientos contempla dos tendencias estilísticas nítidamente diferenciadas: por una parte, aquellos músicos que permanecen fieles a los postulados conservadores del contrapunto imitativo que tiene sus raíces en el Renacimiento y, por otra, los compositores que se adscriben al nuevo estilo moderno o armónico, empleando en su producción artística las formas provenientes del teatro dramático-musical italiano, así como una serie de recursos armónicos prohibidos en la técnica contrapuntística.

Por primera vez en la estética musical se plantea la concepción de la música. Una primera tesis, propiciada por el espíritu cartesiano de los franceses, opta por considerar la música como producto de la razón, caso en el cual es una ciencia con reglas inamovibles porque la razón es la verdad. Por lo tanto, el deleite en la apreciación del arte de los sonidos consistirá en la comprobación de que la música es una ciencia sujeta a principios universales, cuyas reglas hay que respetar en todo momento. La segunda tesis, apoyada en la libertad que propugnan los italianos, sustenta que el origen de la música es el arte, el sentimiento, donde tienen cabida el placer, la imitación de la naturaleza entendida como espontaneidad y expresividad, y la emoción, cuyo juez supremo será el oído como definidor de lo que es conveniente o negativo en música, dejando al margen las reglas científicas ${ }^{1}$.

Prueba del antagonismo de ambas concepciones en la España dieciochesca es la polémica entre Francisco Valls, maestro de capilla de la catedral de Barcelona, y Joaquín Martínez de la Roca, organista de la catedral de Palencia, a causa de la composición de la misa Scala aretina de Valls, en cuyo Gloria hizo entrar el tiple segundo sin preparación, produciéndose una disonancia directa. No menos de cincuenta y cinco compositores y teóricos intervinieron en la po-

1 Enrico Fubini, La estética musical desde la Antigüedad hasta el siglo XX, Madrid, Alianza Música, 1985, págs. 199-205. 
lémica, entre ellos el célebre Alessandro Scarlatti, a quien se consultó para que resolviera con su autorizada opinión una polémica que ya duraba muchos años y que había gastado ríos de tinta. Muy diplomáticamente, Alessandro Scarlatti no se inclinó por ninguna de las partes. Es muy interesante el estudio de esta polémica, como el de otras muchas que hubo con el mismo talante, porque muestran claramente las dos tendencias y los autores de la España musical del siglo XVIII ${ }^{2}$.

El propio Francisco Valls resume la diversidad de estilos imperantes en la música española del siglo XVIII: el estilo eclesiástico, canónico o motético, característico de la música vocal latina; el estilo madrigalesco, propio de «nuestros villancicos a pocas o muchas voces, consiste su práctica en vestir aquella poesía según los afectos que la acompañan»; el estilo melismático se basa en «cantar las voces unidas, sin paso ni intención para que no se confunda la letra»; el estilo fantástico corresponde al instrumental: «sirve su uso para música de órgano, clavicémbalo, arpa, guitarra [...]»; el estilo dramático o recitativo es «el propio para Comedias y Tragedias, precisado no sólo a seguir las leyes del metro, sino a expresar los mismos afectos en la música y que debe exprimir el cantante [...]»; por último, el estilo coraico es «el que sirve para danzas y bailes» ${ }^{3}$.

Podríamos resumir el panorama musical español del siglo XVIII hablando de tres ámbitos: la música eclesiástica, la música de cámara y la música teatral, que siguen siendo los mismos del siglo anterior. De los tres ámbitos antes mencionados, el eclesiástico es el que ejerce una mayor influencia, debido a la implantación de la Iglesia en todo el país: en las catedrales, parroquias, monasterios, abadías, colegiatas, etcétera, se mantiene la tradición de la música eclesiástica, para la que trabajaron y siguen trabajando un buen número de compositores españoles, en calidad de maestros de capilla, fundamentalmente. Entre las obligaciones de un maestro de capilla en la España del siglo XVIII se cuentan la composición de música para el culto religioso, dirigir la capilla musical, instruir y cuidar de los niños cantorcicos, así como contratar nuevos cantores y ministriles para la capilla. Asimismo, el maestro tiene la obligación de componer obras nuevas para determinadas festividades - Semana Santa (época en la que se componían sobre todo lamentaciones), Corpus, festividades del lugar o de la iglesia y Navidad—, mientras que para otras fiestas se podía recurrir a las obras de archivo.

2 Sobre esta querella véanse los documentados estudios de Antonio MArTín Moreno, «Algunos aspectos del barroco musical español a través de la obra teórica de Francisco Valls (1665?-1747)», Anuario Musical, vol. XXI-XXII (1976-1977), págs. 157-194, y José López-CALo, La controversia de Valls. I Textos (1). Ejemplar de Granada, Granada, Centro de Documentación Musical de Andalucía, 2005.

3 Véase Antonio Martín Moreno, Historia de la Música Española. 4. Siglo XVIII, Madrid, Alianza Música, págs. 449-450. 
En la música vocal religiosa predomina una gran diversidad de estilos y procedimientos, incluidos los procedentes del teatro musical italiano, lo que ocasionará la reacción de los compositores y teóricos más apegados a la tradición, así como de los cabildos catedralicios. Los compositores españoles escribirán sus obras vocales religiosas de manera muy diferente según la obra esté en latín o en español: para las obras latinas se recurre a un estilo solemne y grave, la prima prattica, que debe conducir al oyente hacia la devoción y meditación; en esta faceta el compositor debe demostrar el dominio de los procedimientos contrapuntísticos por encima de la inteligibilidad del texto, prevaleciendo la intencionalidad de lo solemne y grandioso. No puede tampoco olvidarse que las obras en latín de los grandes maestros españoles de la época de oro de la música española - Morales, Guerrero, Victoria, Vivanco, Torrentes, Ceballos o Loboen ningún momento dejaron de cantarse y copiarse. Por lo que se refiere a las obras en castellano, nos enfrentamos ante la concepción de la seconda prattica, o estilo moderno, que es el mismo que impera en la música vocal profana: además del uso de la técnica nota contra nota, se busca una mayor adaptabilidad de la música al contenido textual.

La mayor parte de los compositores españoles del siglo XVIII es bilingüe, es decir, abordan tanto el estilo contrapuntístico como el armónico y emplearán uno u otro según la finalidad de la obra. Esta práctica está tan asumida que en las oposiciones a las plazas vacantes de maestro de capilla se exige poner música a un texto en latín y a un texto en español.

Por lo que respecta a la música de cámara, es fomentada en círculos relacionados con la corte o la nobleza. Así, el teórico alemán J. G. Walther define la música de cámara en su obra Musicalisches Lexicon (1732) como «diejenige, welche in grosser Herrenzimmern pflegt aufgeführt zu werden» ${ }^{4}$.

En la corte es necesario diferenciar a los músicos de la Real Capilla, cuya función se dirige exclusivamente al culto religioso, de los músicos de la Cámara o los maestros de los reyes y otros miembros de la familia real. Los músicos de cámara tienen como función amenizar las sesiones de los monarcas y su corte, toman parte en las principales festividades de carácter profano, etcétera. Hay que destacar el hecho de que los gustos personales de los monarcas o del noble para los que trabaja el músico son determinantes a la hora de entender este repertorio. Ya en la época de los Austrias, la música de cámara había desempeñado un papel de primer orden. Con la llegada de los Borbones, las primeras influencias son francesas, influencias que pronto van a ser sustituidas

\footnotetext{
4 «Es aquella música que suele cultivarse en las estancias de los grandes señores». Johann Gottfried Walther, Musicalisches Lexikon, Leipzig, 1732, pág. 130 (ed. facs., Kassel, Bärenreiter-Verlag, 1953).
} 
por las italianas, sobre todo desde el momento en que Felipe $\mathrm{V}$ se case con la princesa italiana Isabel de Farnesio. En el ámbito de la música cortesana de cámara ejercerán su actividad creativa autores como Domenico Scarlatti, Sebastián Albero, el padre Antonio Soler, Luigi Boccherini o Gaetano Brunetti. Respecto a la segunda faceta de la música de cámara, la música nobiliaria, son varias las casas nobiliarias que cultivan el mecenazgo y la protección musical en España. La más destacada es sin duda la Casa de Alba, a la que Subirá dedicó un amplio y exhaustivo estudio. Para la Casa de Alba compusieron obras de cámara Gaetano Brunetti, Francesco Montali, José Herrando, Luis Misón y Manuel Canales, autor este último de los primeros cuartetos compuestos por un español.

Por último, el tercer ámbito al que anteriormente hacíamos referencia está protagonizado por la música teatral, en la que podemos observar dos tipos de manifestaciones: en primer lugar, una música teatral de carácter popular, a la que tiene acceso el pueblo llano, ejemplo de lo cual sería la tonadilla escénica, género típicamente español que nace como reacción a la ópera italianizante. En segundo lugar, la música teatral cortesana y nobiliaria, ambas compitiendo entre sí en cuanto a la fastuosidad y grandiosidad en las representaciones escénicas. Antonio Martín Moreno afirma que «desde fines del siglo XVI, con la aparición de la ópera, la música teatral está siempre presente en la vida social y en las discusiones estéticas de la época. En España el teatro es la gran pasión de los siglos XVII y XVIII y a él tiene acceso todo el mundo mediante el pago de la entrada correspondiente. Un elemento espectacular de suma importancia es la música en el teatro, esto cuando no todo él es en música como ocurre con la ópera $»^{5}$. La ópera italiana recibirá su mejor acogida en la corte, y prueba de ello es el elevado número de compositores italianos que vienen a España llamados por los Borbones o atraídos por el ambiente propicio para todo lo que proceda de Italia. La presencia de los compositores italianos y la protección que gozaron por parte de la corte no significa que los españoles no abordaran la música teatral. Entre los principales operistas destacan Sebastián Durón, Antonio Literes y José de Nebra. La evolución de la zarzuela se plasma en la introducción de temas populares y en el abandono de temas histórico-mitológicos. La renovación de la música escénica española tiene en el escritor Ramón de la Cruz a uno de los principales artífices, quien colaboró con compositores como Antonio Rodríguez de Hita, Antonio Palomino, Pablo Esteve, Antonio Rosales y Ventura Galván. La tonadilla es-

5 Martín Moreno, Historia de la Música Española. 4. Siglo XVIII, pág. 341. 
cénica $^{6}$, forma lírico-dramática que emplea motivos de carácter popular, llega a desplazar a la zarzuela en las preferencias del público a lo largo del siglo XVIII. La tonadilla que se independiza y adquiere entidad propia se denomina tonadilla escénica y fue el compositor Luis Misón quien otorgó la nueva forma de la tonadilla a partir de 1757. Entre esta fecha y 1790 se desarrolla la época de oro de este género. Además de Misón, sobresalen como compositores de tonadillas Antonio Guerrero, Blas de Laserna, Pablo Esteve, Pablo del Moral, Antonio Rosales, Jacinto Valledor, Ventura Galván, Antonio Palomino, Guillermo Ferrer y Manuel García.

\section{La música de tecla española en el siglo XVIII}

Una de las cuestiones más debatidas de la musicología española se centra en la existencia de una escuela española de tecla durante el siglo XVIII. Tradicionalmente se ha magnificado la importancia de Domenico Scarlatti en la consolidación del estilo español en la música de tecla dieciochesca y su correspondiente influencia en los compositores ibéricos. Sin embargo, si tenemos en cuenta las diferencias estilísticas con otros compositores españoles de su época, como Sebastián de Albero, Vicente Rodríguez ${ }^{7}$ José de Nebra o José Herrando, así como la escasez de manuscritos, no parece que las sonatas de Scarlatti se hayan difundido más allá del círculo cortesano.

En mi opinión, puede afirmarse que ha existido un estilo propio español en la música de tecla del XVIII. Santiago Kastner fue uno de los primeros musicólogos en resaltar este hecho cuando afirmó que los compositores ibéricos para tecla evolucionan independientemente de la influencia de Domenico Scarlatti. La sonata bipartita se derivaría de la tocata en unos compositores, de la fuga en otros, e incluso de otros elementos de la suite, con su característico esquema

6 Sobre la tonadilla escénica, véase el tratado clásico de José Subirá, La tonadilla escénica, Madrid, Real Academia Española, 1928-1930. Otros estudios más recientes ofrecen una visión más actualizada, tal como puede observarse en el libro colectivo Teatro y música en España: los géneros breves en la segunda mitad del siglo XVIII, ed. de Joaquín Álvarez Barrientos y Begoña Lolo, Madrid, Universidad Autónoma de Madrid y Consejo Superior de Investigaciones Científicas, 2008, o en los artículos de Begoña LoLo, «La tonadilla escénica, ese género maldito", Revista de Musicología, xxv-1 (2002), págs. 439-469; "Itinerarios musicales en la tonadilla escénica», en Paisajes sonoros en el Madrid del siglo XVIII, Madrid, Ayuntamiento de Madrid, 2003, págs. 14-31; «La tonadilla escénica», Scherzo, núm. 176 (2003), págs. 113-124; y «Donde menos se piensa o Manuel García intérprete de tonadillas en los teatros de Madrid (1798-1799)», en Manuel García: de la tonadilla escénica a la ópera española (1775-1832), Cádiz, Centro de Documentación Musical de Andalucía y Universidad, 2006, págs. 137-158.

7 Sobre este autor véase el magnífico estudio de Águeda Pedrero-Encabo, La sonata para teclado. Su configuración en España, Valladolid, Universidad de Valladolid, 1997. 
bipartito, pero sobre todo del tiento: el desarrollo natural de los tientos llenos y los tientos partidos conduce hacia la sonata bipartita que se practica en la Península con anterioridad a la llegada de Domenico Scarlatti a Lisboa en 1721, de donde pasó posteriormente a España ${ }^{8}$.

Incluso los elementos que caracterizan la música clavecinística de Scarlatti tienen un origen hispano o bien su práctica se había consolidado en España y Portugal antes de la llegada del compositor napolitano. Buena prueba de la independencia y originalidad de la escuela española de tecla nos la ofrecen Sebastián de Albero y José de Nebra en la primera mitad del siglo XVIII. En cuanto al primero de los compositores mencionados ${ }^{9}$, a pesar de ser contemporáneo de Scarlatti y prestar sus servicios en la corte al mismo tiempo que él, escribe una música que se inserta en la tradición española de la recercata y el tiento, contribuyendo también al desarrollo de la naciente sonata, a la que aporta la tradición ibérica derivada de la escritura armónica y vertical de los organistas españoles en los ya citados tientos partidos. Por su parte, las sonatas para tecla de José de Nebra muestran, asimismo, un estilo compositivo muy personal; acerca de dichas sonatas escribe el musicólogo Román Escalas que «afirman la existencia y desarrollo de un estilo español de música de tecla a partir de la primera mitad del siglo XVIII, en que la forma, el tratamiento de la disonancia, la vivacidad rítmica, el cromatismo y su relación con la tonalidad no difieren en nada de lo que hasta ahora se habían considerado atributo del estilo personal de Scarlatti y que debemos rescatar como elementos propios de nuestra música, a fin de centrar y definir el concepto de Sonata española para tecla» ${ }^{10}$.

El hecho de no haberse impuesto en España la forma de sonata del clasicismo vienés con su esquema ternario no debe interpretarse como un defecto, en opinión de Kastner. Por el contrario, es necesario comprender que los esquemas constructivos centroeuropeos son muy distintos de los países del sur de Europa y no hay que preferir uno a otro. Por otra parte, la forma clásica de la sonata vienesa la vamos a encontrar en los compositores españoles de finales de siglo, como Joaquín Prieto, Joaquín Montero, José Lidón o Felipe Rodríguez, aunque

8 Santiago Kastner: Antonio Soler: 2+2 Sonatas, Maguncia, Schott, 1956, prólogo.

9 Sobre Sebastián de Albero, consúltense los trabajos de Antonio Baciero (ed.), Sebastián de Albero: Sonatas, Madrid, Real Musical, 1978; Genoveva GÁLvEz (ed.), Sebastián de Albero: treinta sonatas para clavicordio, Madrid, Unión Musical Española, 1978; María Gembero, «La formación musical de Sebastián de Albero (1722-1756): nuevas aportaciones», en España en la música de occidente, vol. 2, Madrid, Ministerio de Cultura, 1987, págs. 109-124; Susanne Sкүrм, «The fugues in Sebastian Albero's Obras para Clavicordio: a second version», en Domenico Scarlatti en España, ed. de Luisa Morales, Almería, Asociación Cultural Leal, 2009, págs. 361-376.

10 Román Escalas, Joseph Nebra (1702-1768). Tocatas y sonata para órgano o clave, Zaragoza, Institución Fernando el Católico, 1987, pág. 7. 
siempre dentro de la influencia establecida por Domenico Scarlatti y Antonio Soler. Concluye diciendo Kastner que no es fácil aceptar los modelos de la sinfonía y sonata de corte y factura vienesa, que responden a la peculiar manera de ser y entender el arte y la vida de estos pueblos, pero cuyas formas son extrañas y ajenas al espíritu conciso y diferente de los latinos ${ }^{11}$.

\section{Domenico Scarlatti}

\section{III.1. TRAYECTORIA VITAL Y ARTí́STICA}

Nacido en Nápoles, la actividad creativa de Domenico Scarlatti ${ }^{12}$ en España significó uno de los momentos culminantes de nuestra historia musical, influyendo decisivamente en varias generaciones de compositores españoles, entre los cuales destacó el padre Antonio Soler. Prolífico compositor, abordó con igual acierto diferentes géneros vocales e instrumentales, pero sobre todo marcó un hito en la génesis de la sonata bipartita monotemática, precursora de la sonata clásica.

Su primera etapa como músico estuvo determinada por la figura y la actividad de su padre, el célebre Alessandro Scarlatti, con quien se formó en primer lugar. Sólo a raíz de su abandono de Italia (1719) y de la muerte de su padre (1725) comenzará a escribir una de las páginas más brillantes de la literatura musical para clave.

En 1701 obtuvo su primer puesto musical al ser nombrado segundo organista y compositor de la Capilla Real napolitana, donde su padre ejercía el magisterio. Posteriormente los Scarlatti se asentaron en Florencia: de esta época datan tres cantatas, sus primeras obras conocidas. A su regreso a la corte de Nápoles, Domenico estrenó sus dos primeras óperas en 1703: Ottavia restituita al trono e Il Giustino, ambas pertenecientes al tipo convencional de ópera seria tardobarroca. Un año después salió de su pluma la ópera L'Irene. Abandonó Nápoles en 1705 para fijar su residencia en Venecia, uno de los grandes centros musicales de la Italia del siglo XVIII, donde reinaban la música de Vivaldi y la pintura de Canaletto; en Venecia perfeccionó sus estudios de composición con

11 Kastner, op. cit., prólogo.

12 Los principales estudios de conjunto sobre este autor son: Ralph KIRKPATRIcK, Domenico Scarlatti, Madrid, Alianza Editorial, 1985; Carole F. Vidali, Alessandro and Domenico Scarlatti: A Guide to Research, Londres, Routledge, 1993; Roberto Pagano, Alessandro and Domenico Scarlatti: Two Lives in one, Oxford, Pendragon Press, 2006; Luisa Morales (ed.), Domenico Scarlatti en España, Almería, Asociación Cultural Leal, 2009; y Paulino Capdepón, «Scarlatti, Domenico», en Diccionario Biográfico Español, Madrid, Real Academia de la Historia, 2011. 
el célebre maestro Francesco Gasparini, cuyas libertades armónicas tendrán una gran influencia en el estilo posterior de Scarlatti.

Cuatro años después, en 1709, entró en Roma al servicio de la antigua reina de Polonia María Casimira, para cuyo teatro escribió un buen número de obras escénicas, tales como la pastoral La Silvia (1710), a la que siguieron las óperas Orlando (1711), Tetide in Sciro (1712), Ifigenia in Aulide e Ifigenia in Tauride (1713), Amor d'un ombra (1714) y Ambleto (1715). Sin embargo, pronto encaminó su talento hacia la creación de obras para teclado, eligiéndole el cardenal Ottoboni para que se enfrentase a Haendel como representante de la escuela italiana de clave; según se ha dicho tradicionalmente, el alemán fue superior en el órgano pero fue superado por Scarlatti en el clave, aunque no existe constancia documental de esta aseveración ${ }^{13}$.

A partir de 1713 desempeñó el puesto de maestro de capilla de San Pedro, institución para la que compuso ante todo obras religiosas destinadas al culto. Tras una breve estancia en Londres, donde trabajó como director de óperas y maestro de clave en el Teatro Italiano (en 1720 representó su ópera Narciso), asumió la función de maestro de capilla del rey portugués João $\mathrm{V}$ y maestro de música de la princesa María Bárbara de Braganza: en Lisboa permanecerá por espacio de ocho años (1720-1728), durante los cuales compuso un elevado número de sonatas para clave, dedicadas a su regia alumna, que al parecer poseía buenas dotes para este instrumento. En reconocimiento a su trabajo en Lisboa y a los servicios prestados en la corte portuguesa, y sin duda debido a la admiración que le profesó su alumna real, João V le nombraría años después (1738) caballero de la Orden de Santiago. El 15 de mayo de 1728, a los cuarenta y tres años, Domenico Scarlatti contrajo nupcias en Roma con María Catalina Gentili, de la que tuvo cinco hijos.

La última etapa de la vida de Domenico Scarlatti transcurrió en España, ya que, con motivo de las esponsales de la princesa María Bárbara de Braganza con el príncipe heredero español Fernando en 1729, aceptó el puesto de maestro de música de ambos príncipes y se trasladó a España, país en el que residió hasta su muerte. Felipe $\mathrm{V}$ y el príncipe de Asturias salieron con la comitiva real el 7 de enero de 1728 para recibir a la princesa portuguesa en Badajoz. Doce días después llegó María Bárbara y se hicieron las velaciones. El 27 de enero de aquel mismo año partieron de Badajoz a Sevilla, donde permaneció la corte hasta el 16 de mayo de 1733, lo cual quiere decir que en la ciudad andaluza Scarlatti permaneció los primeros cinco años de su estancia en España en calidad de clavicembalista y maestro de la princesa María Bárbara, antes de

13 Martín Moreno, Historia, pág. 227. 
trasladarse a Madrid en el otoño de 1733: este hecho explicaría los numerosos rasgos «andaluces» de su música. Nicolás Álvarez Solar Quintes sacó a la luz en el archivo de palacio, en las cuentas denominadas «Mesillas de la jornada a Andalucía, desde abril de 1732», el siguiente documento referido al compositor italiano: «A D. Domingo Escarlatti, Maestro de Música de la Princesa nra. Sra., al respecto de 90 Reales diariamente, le corresponden en 418 días últimos de dicha Jornada de Andalucía 37.620 rs., en cuenta de los cuales tiene recibido por la maestría 24.200 y se le restan debiendo $13.420 »^{14}$. Sus relaciones con Andalucía y Sevilla no finalizaron en 1733, pues su hijo Juan Antonio Scarlatti obtuvo el beneficio simple de la iglesia parroquial de Alíjar (arzobispado de Sevilla) desde 1749 hasta su muerte, acaecida probablemente en 1762, año en el que otro de sus hijos, Fernando, obtuvo el mismo beneficio después del fallecimiento de su hermano.

Si durante los primeros años de su estancia española Scarlatti disfrutó de una posición preeminente en el mundo musical cortesano, la llegada en 1737 de su compatriota Farinelli eclipsó la figura del napolitano, que se limitó a componer únicamente para el clave: entre sus obligaciones, debía tocar el clave todas las noches ante la familia real y componer únicamente para este instrumento, ya que la música teatral era responsabilidad única de Farinelli. No podemos olvidar, sin embargo, la faceta docente de Scarlatti: además de la enseñanza de la reina María Bárbara, adiestró a un buen número de compositores españoles. Una vez que enviudó, se casó en segundas nupcias con Anastasia Marxati, de la que tuvo otros cuatro hijos. Domenico Scarlatti falleció el 23 de julio de 1757 en su casa madrileña de la calle de Leganitos.

La mayor parte de su obra vocal se remonta a su etapa italiana. Por lo general, su producción religiosa se enmarca dentro del stile antico del siglo XVI al demostrar un gran conocimiento de la música de Palestrina, si bien recurre al melodismo propio del barroco tardío ${ }^{15}$.

\section{III.2. LAS SONATAS PARA TECLADO ${ }^{16}$}

Sobre el alcance de la influencia de Scarlatti en la génesis e implantación de la sonata para teclado en España se ha discutido ampliamente. Pese a todo,

\footnotetext{
14 Nicolás Álvarez Solar Quintes, «Documentos sobre la familia de Domenico Scarlatti», Anuario Musical, IV (1949), pág. 140.

15 Andrés Ruiz Tarazona, «Scarlatti, Domenico», en Diccionario de la Música Española e Hispanoamericana, vol. 9, Madrid, SGAE, pág. 855.

16 Véase nuestro trabajo de síntesis sobre las sonatas de Scarlatti: Tecla española del siglo XVIII, Madrid, Fundación Juan March, 2007.
} 
no se puede negar a Scarlatti tanto haber llevado el modelo de sonata bipartita monotemática a su perfección como haber creado una escuela en nuestro país, de la que surgieron autores tan emblemáticos y decisivos para la historia de la música dieciochesca en España como el padre Antonio Soler, uno de los compositores más sobresalientes del panorama musical español de aquella época.

La primera colección de sus sonatas para clave apareció en 1738 en Londres bajo el título de Essercizi per Gravicembalo y están dedicadas al rey de Portugal. Merece la pena citar un fragmento del prólogo escrito por el propio Scarlatti pues deja entrever cuál era su objetivo: «Lector, no esperes encontrar en estas composiciones una intención profunda, sino más bien una ingeniosa broma artística para ejercitarte en el duro ejercicio de tocar el clave [...]. Por tanto, muéstrate más comprensivo que crítico y, de esta manera, verás aumentado considerablemente tu propio placer. Hasta siempre. ¡Vive feliz!». Según el gran estudioso y editor de la obra para teclado de Scarlatti, Ralph Kirkpatrick, entre 1752 y 1757 fueron transcritos trece volúmenes de sonatas para el uso de la reina María Bárbara de Braganza, a los que se unieron dos más, compilados en 1742 y 1749. Estos quince volúmenes, adquiridos en 1835 por la Biblioteca Marciana de Venecia, contienen un total de 496 sonatas. Otra colección de quince volúmenes, en parte réplica de la anterior, se conserva en la actualidad en el departamento de música de la Biblioteca Palatina del Conservatorio Arrigo Boito de Parma ${ }^{17}$. A estas fuentes principales hay que añadir tres sonatas descubiertas por Antonio Baciero en un manuscrito del archivo de la catedral de Valladolid y la sonata y el fandango que rescató la musicóloga Rosario Álvarez en un archivo tinerfeño en $1985^{18}$. Otras fuentes secundarias se encuentran en Múnich, Viena, el Museo Británico de Londres, el Museo Fitzwilliam de Cambridge, la Biblioteca Nacional Universitaria de Turín y las ediciones de Roseingrave y Boivin (siglo XVIII).

La mayor parte de las sonatas de Scarlatti muestran una estructura formal bipartita en un solo movimiento y monotemática, cuyo esquema básico, siguiendo a Kirkpatrick, es el siguiente: 1. Primera mitad: 1.1 Inicio. 1.2 Sección central (Continuación, transición, prenúcleo). 1.3 Núcleo. 1.4 Sección tonal (postnúcleo, conclusión, continuación de la conclusión, sección final de la conclusión). 2. Segunda mitad: 2.1 Inicio (opcional). 2.2 Digresión. 2.3 Reenunciado opcional del prenúcleo o del material precedente 2.4 Núcleo 2.5 Reenunciado de la sección tonal (postnúcleo, conclusión, continuación de la conclusión, sección final de la conclusión). Sin embargo, se dan excepciones a

17 KirKPATRicK, op. cit., pág. 422 y ss.

18 Rosario Álvarez, «Dos obras inéditas de Domenico Scarlatti», Revista de Musicología, vol. 8, núm. 1 (1985), págs. 51-56. 
este esquema básico propuesto por Kirkpatrick. Mientras que la sonata clásica tiende a la forma en tres partes, la sonata scarlattiana mantiene una relación de equilibrio o complementaria entre sus mitades, aun cuando no tengan la misma longitud. La verdadera esencia se encuentra en la sección central de la primera mitad, y en la que es paralela a ésta en la segunda; en estas dos secciones se divide la energía que late en la sonata clásica. Normalmente, la sección central de la segunda mitad nunca rebasa en extensión a su paralela. Los polos de la sonata del compositor italiano residen en esta sección central, en la que culminan las tensiones en la dominante que se resuelven en la tonalidad de conclusión. Todas las fuerzas armónicas y de invención melódica están orientadas a preparar la resolución final en la tonalidad de conclusión. El núcleo es el punto de encuentro del material temático en cada mitad, que aparece enunciado de manera paralela en los finales de ambas mitades, al quedar establecida la tónica de conclusión. El núcleo no tiene importancia para el oyente o el intérprete, pero permite establecer un sistema de análisis para esta sonata scarlattiana. En cada mitad de la sonata, el núcleo surge en el momento en que se hace diáfana la tonalidad de conclusión, bien por el establecimiento de su dominante o, de manera más rara, por una cadencia preliminar a la tónica de conclusión; en general, la tonalidad de conclusión sigue impertérrita tras el núcleo. El núcleo puede aparecer realzado por una interrupción brusca o estar oculto por un movimiento rítmico continuo. Usando este concepto como punto de partida, es posible identificar las diversas partes o secciones de la sonata scarlattiana; son divisiones anatómicas creadas por Kirkpatrick para facilitar y dar precisión al análisis de las sonatas ${ }^{19}$.

El propio Kirkpatrick ha demostrado que buena parte de estas sonatas estaban ordenadas por parejas y compuestas en la misma tonalidad, parejas que se contrastan o se complementan. El contraste se basa en el tempo (a un movimiento de carácter rápido le sucedía uno lento), mientras que en las sonatas complementarias la uniformidad residía en el estilo o en el mismo colorido armónico (así, por ejemplo, aunque la sonata K 107 está compuesta en fa mayor, se mueve alrededor de fa menor y sus tonalidades relativas $)^{20}$. Si bien las sonatas de Scarlatti se atienen a un esquema tonal preciso y predeterminado (tónica-dominante-tónica), traspasan las limitaciones de este rígido sistema y en el inicio de la segunda parte de muchas de sus sonatas se ofrece una idea nueva o bien modifica el tema inicial, logrando así propiciar un clima diferente: todavía no puede hablarse de un desarrollo, a la manera del estilo clásico vienés, sino

\footnotetext{
19 KiRKPATRick, op. cit., pág. 213 y ss.

20 Ibidem, pág. 122.
} 
que se relaciona más bien con la técnica de la progresión, de la expansión o de la secuencia. Aun así, supone un salto cualitativo trascendental que antecede y anuncia el esquema de la sonata moderna.

Además de la forma bipartita de un solo tiempo y monotemática, las sonatas de Scarlatti también presentan otras formas: variaciones, fugas, rondós, un capriccio, mientras que otras aportan la peculiaridad de tener dos, tres o cuatro movimientos. Gracias a Scarlatti se tomó conciencia de las posibilidades tímbricas y expresivas del instrumento, anunciando buena parte de los elementos de la técnica pianística: cruzamientos de manos, técnica de la velocidad, acordes autónomos, marcha de las voces nacida del movimiento natural de los dedos, notas repetidas rápidas, trinos interiores, etcétera. Por otra parte, el empleo de la acciaccatura (largas series de apoyaturas suspendidas que se resuelven unas en otras) introdujo disonancias que preludian asimismo la armonía moderna ${ }^{21}$.

Muchas de sus sonatas evocan la música popular de su Italia natal, con ecos de mandolina o laúd y, además, la abundancia de adornos no son sino reflejo del gusto de los napolitanos por lo decorativo. Asimismo, son frecuentes los préstamos del folclore español: imita los timbres característicos de los instrumentos populares, como el rasgueo de la guitarra, el repiqueteo de las castañuelas o la reverberación de los tambores, la alegría contagiosa de las bandas de pueblo, la flexibilidad de la danza española, además del empleo de intervalos modales en sus melodías (buen ejemplo de ello es la sonata K 481). Domenico Scarlatti realizó en su evolución como compositor una extraordinaria síntesis estilística de la sonata: si en las primeras obras se percibe el peso de la tradición por la relación con la tocata o la textura puramente organística, otras acusan la deuda con el estilo del concierto instrumental y la técnica del violín, así como con el estilo preclásico (como se observa en la sonata K 11 en do menor, la cual muestra la melancólica cantabilidad del estilo sensible o Empfindsamkeit) ${ }^{22}$. A partir de 1752, el estilo de sus sonatas deja entrever la madurez del compositor: la fluidez de ideas contrastantes, la libertad en el empleo de acordes y vías modulatorias, el lirismo, a veces nostálgico, de sus líneas melódicas o el exuberante virtuosismo de sus saltos y cruces de manos son algunas de sus características más llamativas. En definitiva, las sonatas de Domenico Scarlatti están impregnadas de frescor, gracia, jovialidad y brillantez: su vigor rítmico les confiere una vitalidad extraordinaria que aún hoy es la causa de su atractivo entre el público moderno.

\footnotetext{
$21 \quad$ Ibidem, pág. 343 y ss.

22 Ibidem, pág. 135.
} 


\section{El padre Antonio Soler}

\section{IV.1. TRAYECTORIA VITAL Y ARTí́STICA ${ }^{23}$}

Nacido en la villa gerundense de Olot, el padre Antonio Soler es una de las principales personalidades de la historia de la música española. Su padre, Mateo Soler, pertenecía a la banda de música del Regimiento de Numancia y es muy probable que de él recibiera el joven Antonio las primeras lecciones musicales. Antes de haber cumplido los siete años de edad, ingresó en la escolanía de Montserrat, en la que permaneció entre ocho y diez años; antes de cumplir los diecisiete años la abandonó: ésta era la edad límite de permanencia en la escolanía. Gracias a su padre poseía formación musical cuando fue admitido como niño de coro en el monasterio de Montserrat. Por entonces era maestro en Montserrat el padre Benito Esteve, mientras que la función de organista era desempeñada por Benito Valls. Bajo la tutela de ambos se inició Soler en el estudio del solfeo, en primer lugar, y del órgano y la composición, posteriormente. Las obras de órgano de Juan Cabanilles, fray Miguel López y José Elías constituían la base del repertorio organístico que los alumnos de la escolanía estudiaban. El mismo Soler afirma que estudió 24 obras para órgano de José Elías.

En la Memoria sepulcral de Antonio Soler se afirma lo siguiente: «Y salió tan adelantado que hizo oposición en dos catedrales al magisterio de capilla, y logró el de la Santa Iglesia de Lérida, hallándose nuestro ilustrísimo señor don Fray Sebastián de Victoria, obispo de Urgel, prior que había sido en este real monasterio de San Lorenzo» ${ }^{24}$. Sin embargo, hasta hoy en día no se ha encontrado documento alguno, ni en el archivo de música ni en las actas capitulares de la catedral de Lérida, que confirme tal noticia. ¿Se debió a un error del redactor anónimo de la Memoria sepulcral? El padre Samuel Rubio defiende la tesis de que Soler obtuvo la maestría de capilla no en Lérida sino en Seo de Urgel, catedral en la que tomó posesión como obispo en 1744 fray Sebastián de Victoria, por lo que las oposiciones no debieron de celebrarse antes de la citada fecha ${ }^{25}$. La última aportación a esta cuestión se debe a José Sierra, quien demuestra la estancia de Soler en Lérida: en la primera obra del compositor, autógrafa, que se conserva en el archivo de música del monasterio de El Escorial, aparece la

23 Véanse nuestros trabajos «El padre Antonio Soler», Anales del Instituto de Estudios Madrileños, vol. 30 (1990), págs. 685-691; «Soler, Antonio», en Diccionario de la Música Española e Hispanoamericana, vol. 9, Madrid, SGAE, págs. 1.122-1.131; El padre Antonio Soler (1729-1783): biografía y obra musical, Olot, Patronat d'Estudis Històrics d'Olot y Comarca, 2000.

${ }^{24}$ Memoria sepulcral de Antonio Soler, fol. 294v. Citado en Samuel Rubio, Antonio Soler: catálogo crítico, Cuenca, Instituto de Música Religiosa de la Diputación, pág. 18.

25 Ibidem. 
frase «Echo en Leri[da]». Con ello no se demuestra que ejerciera el magisterio de capilla en Lérida, si bien Sierra apunta dos posibilidades: la pieza pudo ser compuesta con ocasión de la oposición que tal vez no llegó a ganar, o bien que Soler fuera maestro de capilla en otro lugar de la capital o provincia de Lérida ${ }^{26}$.

Fue admitido como novicio en el monasterio de El Escorial «por los buenos informes que se tenía de su genealogía y limpieza, de su suficiencia en la latinidad y por ser tan notoria su habilidad en el órgano y en la composición ${ }^{27}$. Los informes sobre su genealogía y limpieza de sangre fueron efectuados en la ciudad zaragozana de Daroca, de donde era originaria su madre, entre los días 3 y 14 de agosto de 1752, y en Porrera, ciudad natal de su padre, durante los días 21 y 22 de agosto. Al poco tiempo, el 12 de septiembre de aquel año dichos informes eran aprobados por el padre prior y sus consejeros. A los ocho meses (15 de junio de 1753) y a los diez meses (28 de julio de 1753) se produce su recepción en el monasterio, y en ambas ocasiones obtiene la aprobación de la comunidad de monjes, según consta en las actas capitulares escurialenses ${ }^{28}$. Tras el año preceptivo de noviciado fue admitido a la profesión, ocasión para la que compuso un Veni Creator a ocho voces y violines, cuya portada dice así: «Compuesto por Fr. Antonio Soler, novicio en este Real Monasterio de San Lorenzo, para el día de su profesión, que será el día 29 de septiembre de 1753». Cuando ingresó en el monasterio de El Escorial, Soler venía precedido de gran prestigio como compositor y organista, ganándose pronto la simpatía y el aprecio de la comunidad, como lo demuestra el acuerdo del 16 de marzo de 1754 por el que se otorga a su padre una pensión vitalicia de cien ducados anuales para que pudiera mantenerse.

No se sabe cuándo fue nombrado diácono, sacerdote y maestro de capilla, pues los nombramientos de maestro de capilla los hacía el padre prior verbalmente, de ahí que no consten en las actas, pero debió de desempeñarlo después de 1757, último año del magisterio del padre Moratilla. Las Apuntaciones para el mejor govierno y instrucción de el Pe. Vicario nos aportan valiosa información sobre la función de maestro de capilla del monasterio escurialense, que es perfectamente aplicable a nuestro compositor, al haber sido escritas años antes de que Soler asumiera el magisterio de capilla:

Este Oficio, por sí solo, aunque tenga que enseñar a los Chicos Tiples o a algunos Religiosos, como alguna vez sucede, no tiene más alivio que el Coro del día, pero suele dársele una vela y con ella está exento de todo Coro, si no es los

26 José SiERra, «Un documento que acredita la estancia del padre Soler en Lérida», Revista de Musicología, vol. V, núm. 2 (1982), pág. 369.

27 Memoria sepulcral, fol. 295r. Citado en Rubio, op. cit., pág. 19.

28 Actas Capitulares del Monasterio del Escorial (AмE), fol. 131r. Citado en Rubio, op. cit., pág. 19. 
Extraordinarios. Hace todos los Oficios correspondientes a su edad sino es el de Canturía. Corren de su cuenta encomendar las Lamentaciones que no se dijeren a Música. Preside en las Grangillas de músicos si tiene veinte años de hábito, y si no, el más antiguo músico que va. Algunos Padres Oficiales han solido darle alguna cosa de los que llaman gages de anciano, aunque el Maestro de Capilla no lo sea, pero esto es gracia y está muy moderado. Asiste a la Oración de Cuaresma si no tiene otro título para excusarse ${ }^{29}$.

En los primeros años de su etapa escurialense, Soler recibió clases de dos célebres compositores: Domenico Scarlatti y José de Nebra. La primera prueba documental de su aprendizaje con aquél nos la ofrece una carta del 27 de junio de 1765 dirigida al padre Martini, en la que el propio Soler afirma que era «scolare dil Sr. Scarlatti» ${ }^{30}$. Además, la edición inglesa de un manuscrito de sonatas para clave que el compositor entregó a un editor inglés, lord Fitzwilliam, incluye un prólogo de éste, en el que escribe lo siguiente: «El original de estas lecciones me lo dio el padre Soler en El Escorial el 14 de febrero de 1772; el padre Soler había tomado lecciones de Scarlatti» ${ }^{31}$. Sin embargo, Miguel Querol rebate la posibilidad de que Scarlatti fuera maestro de Soler: primero, porque la labor de organista de éste apenas le dejaría tiempo libre; en segundo lugar, porque Scarlatti sería ya un hombre mayor por aquella época, al cual le quedarían pocas ganas de enseñar, y, por último, porque el padre Soler no tendría nada que aprender de Scarlatti que no hubiera aprendido ya ${ }^{32}$. En cualquier caso, estas razones no demuestran que Soler no haya estudiado con Scarlatti.

Su otro maestro fue José de Nebra ${ }^{33}$, uno de los más eminentes compositores españoles del siglo XVIII, el cual se pronunció elogiosamente sobre su alumno en la Censura del libro de Soler Llave de la modulación y Antigüiedades de la música. Rubio opina que las clases con Scarlatti y Nebra se pudieron desarrollar bien en el propio monasterio o en Madrid ${ }^{34}$. En El Escorial, porque la corte tenía su sede en el monasterio durante parte del año; tanto Nebra y Scarlatti, en su

29 Apuntaciones para el mejor govierno y instrucción de el Padre Vicario, fol. 100r., Archivo General de Palacio, leg. 1804. Citado en José Hernández, Música y culto divino en el Real Monasterio de El Escorial, San Lorenzo de El Escorial, Ediciones Escurialenses, 1993, pág. 490.

30 Santiago KASTNER, «Algunas cartas del padre Antonio Soler dirigidas al padre Giambattista Martini», Anuario Musical, vol. XII (1957), pág. 237.

31 XXVII Sonatas para Clave, Que ha impresso Roberto Birchall, Nr. 133, New Benet Street, Londres 1796. Citado en Rubio, Catálogo crítico, pág. 20.

32 Miguel Querol, El padre Antonio Soler (1729-1783), Olot, Patronat d'Estudis històrics d'Olot y Comarca, 1979, pág. 7.

33 Una completísima biografía sobre este compositor fue escrita por Maria Salud Álvarez, José de Nebra Blasco. Vida y obra, Zaragoza, Institución Fernando el Católico, 1994.

34 Rubio, Catálogo crítico, pág. 21. 
calidad de músicos cortesanos, se instalaban en El Escorial acompañando a la corte. Por otra parte, en su obra teórica Llave de la modulación Soler habla del convento de los jerónimos de Madrid y de la hospedería que se encontraba a su lado como algo familiar para él. Asimismo, en su libro Satisfacción a los reparos hechos por don Antonio Roel del Río, a la llave de la modulación (1765) dice que había escuchado en sus respectivas capillas diversas obras de los maestros que censuraron y aprobaron su libro Llave de la modulación, es decir, Francisco Corselli y José de Nebra, maestro y vicemaestro de la real capilla; Antonio Ripa, maestro de capilla del monasterio de las Descalzas Reales; José Mir, maestro de capilla del monasterio de la Encarnación, y Nicolás Conforto, maestro de música de las infantas ${ }^{35}$. Por todo ello, es más factible suponer que dichas lecciones de música con Nebra y Scarlatti tuvieran lugar en Madrid. Éste fue también el caso de varios músicos escurialenses anteriores a Soler, como Juan de Alaejos, José del Valle y Manuel del Valle, teniendo estos dos últimos como profesor a José de Nebra.

Desde el primer momento en que asumió el magisterio de capilla escurialense, a partir de 1757, se encargó de aprobar el ingreso de nuevas voces e instrumentistas en la capilla musical de El Escorial en las personas de los novicios recién llegados. Tales intervenciones de Soler son propias de cualquier maestro de capilla en la España del siglo XVIII. La propia comunidad jerónima costeó en 1762 la publicación de la primera obra teórica del padre Soler, titulada Llave de la modulación. Tras las pertinentes aprobaciones, la obra se imprimió en un tomo en la imprenta de Ibarra y se puso a la venta a finales de octubre de 1762 . En 1767 la comunidad otorga un poder a Soler para que pueda seguir una demanda en el pueblo tarraconense de Porrera sobre un vínculo heredado de su padre $^{36}$. En 1776 trabajaba en un tratado en varios tomos sobre la «música eclesiástica antigua, inocente, clara y devota», según él mismo relata en una carta del 2 de julio de aquel año al padre Martini ${ }^{37}$. Esta obra, que en 1771 estaba muy avanzada, no se ha conservado. En opinión de Samuel Rubio, es probable que parte de los materiales recogidos por Soler fueran aprovechados por su amigo José Teixidor para escribir sus obras Discurso histórico sobre la música religiosa y Discurso sobre la historia universal de la música ${ }^{38}$.

Al menos en 1766 había recibido el encargo de responsabilizarse de la formación musical de los infantes don Antonio y don Gabriel, hijos de Carlos III,

\footnotetext{
35 Antonio Soler, Satisfacción a los reparos hechos por don Antonio Roel del Río, a la llave de la modulación, Madrid, Imprenta de Antonio Marín, 1765, pág. 65.

36 AME, II, 7 de noviembre de 1767, fol. 201v.-202r. Citado en HERnández, op. cit., pág. 471 y ss.

37 KASTNER, «Algunas cartas del padre Antonio Soler», pág. 238.

38 Rubio, Catálogo crítico, pág. 22.
} 
ya que en una carta del 30 de noviembre de 1766 al padre Martini se refiere a tal circunstancia: «[...] essondo stato occupatatissimo p. le Persone Reali [...]» ${ }^{39}$. Para don Gabriel ${ }^{40}$ compuso gran parte de su música instrumental: las sonatas para clave y, especialmente, los cinco conciertos para dos órganos que el monje jerónimo y el infante interpretaban juntos. En algunas de las obras escritas con tal fin se afirma que fueran compuestas «para la diversión del Ssmo. Infante de España Don Gabriel de Borbón».

Don Gabriel tomó tal cariño al humilde y sencillo monje escurialense que apenas acertaba a separarse de él. Soler compuso sus seis Quintetos para ser interpretados en la Casita de arriba o del Infante, actuando el infante como clavicembalista. La función de maestro del infante don Gabriel y su labor como maestro de capilla del monasterio de El Escorial, en donde la corte permanecía largas temporadas, hicieron que Soler tuviera la oportunidad de frecuentar a los más destacados compositores españoles de su tiempo.

En relación al órgano, Soler no se limitó a su labor interpretativa en calidad de organista y maestro de capilla del monasterio de El Escorial. Asimismo, había estudiado el arte de la construcción de órganos, de tal manera que fue consultado por los más destacados organeros de España, uno de los cuales, José Casas, que era también organero de El Escorial, había finalizado la construcción de un gran órgano en la catedral de Sevilla. Los organistas de la catedral hispalense, sin embargo, objetaron reparos a la labor de Casas, reparos que fueron solventados por el constructor. Dado que no le acababan de pagar la última parte convenida, solicitó consejo al padre Soler, el cual escribió una amplia y erudita carta al cabildo de la catedral sevillana, saliendo en defensa de Casas: dicha carta fue publicada en la imprenta de Andrés Ramírez en $1778^{41}$. Dos años antes, en 1776, había recibido el encargo de realizar un proyecto sobre la construcción de un gran órgano en la catedral de Málaga.

La incesante actividad de Soler no parecía tener límite. Deseando demostrar la exacta división matemática o cromático del tono musical, construyó un pequeño instrumento con teclas y cuerdas, parecido al clave, al que denominó afinador o templante. Construyó dos ejemplares, uno para el infante don Gabriel y otro para el duque de Alba, ninguno de los cuales se ha conservado. Pero sus intereses no se limitaban a la música. Era un gran aficionado a las

39 Kastner, «Algunas cartas del padre Antonio Soler», pág. 238.

40 Sobre la vida del infante don Gabriel, véase Juan Martínez Cuesta, Don Gabriel de Borbón y Sajonia. Mecenas ilustrado en la España del Carlos III, Valencia, Real Maestranza de Caballería de Ronda y Editorial Pre-Textos, 2003.

${ }^{41}$ Biografías y documentos sobre música y músicos españoles (Legado Barbieri), vol. I, edición a cargo de Emilio Casares, Madrid, Fundación Banco Exterior, 1986, pág. 460. 
matemáticas, como lo demuestra en las numerosas operaciones matemáticas que incluye en su Llave y en las obras publicadas posteriormente en defensa de la citada obra. Publicó asimismo Combinación de Monedas y Cálculo manifiesto contra el Libro anónimo intitulado: Correspondencia de la Moneda de Cataluña a la de Castilla, editado en 1771. La Memoria sepulcral nos ofrece de nuevo datos de su personalidad humana, según los cuales fue un monje continuamente ocupado en sus labores espirituales y artísticas. Esta dedicación plena al trabajo motivará constantes recaídas en su salud, que lo obligaron a reponerse en la enfermería del monasterio ${ }^{42}$. Antonio Soler falleció el 20 de diciembre de 1783 a los cincuenta y cuatro años en el monasterio de San Lorenzo de El Escorial.

Por lo que se refiere a su producción musical, se puede dividir en tres grandes apartados: música vocal, música instrumental y música teórica. En cuanto a la música vocal latina, el padre Soler domina los dos estilos predominantes en la música española del siglo XVIII: el estilo polifónico o prima prattica, relacionado con la música renacentista, y el denominado estilo moderno o armónico, denominado asimismo seconda prattica. Así, por ejemplo, sus misas, tanto de Gloria como de Difuntos, participan de ambas estilos. En todo caso, sólo un pequeño número de obras puede adjudicarse al primer estilo, estilo que está presente en El Escorial, ya que las obras de los grandes maestros del Renacimiento como Morales o Victoria seguían interpretándose, influenciando su estética la concepción musical de los maestros del barroco español, por lo que los avances de la moderna tonalidad se asentaron en España más tarde que en otros países. Respecto al segundo estilo, denominado moderno o armónico, su introducción en España está relacionada con la implantación de la homofonía y la adopción de las formas provenientes del teatro musical italiano: el bajo continuo, el mayor papel protagonista de los instrumentos, el uso del recitado y del aria, la ornamentación de las líneas vocales, el virtuosismo vocal, etcétera. Puede afirmarse que gran parte de la obra vocal religiosa en latín del padre Soler se adscribe a este segundo estilo musical. Para el padre Samuel Rubio, gran estudioso de la obra soleriana, la facilidad de inspiración del padre Antonio Soler perjudicó la profundidad de su obra vocal religiosa ${ }^{43}$.

Uno de los géneros más significativos en la obra religiosa de Soler es el villancico. Desde el punto de vista del contenido temático, cabe distinguir cuatro modelos principales en los villancicos de Antonio Soler: 1) Villancicos

42 Memoria sepulcral, fol. 295r.-296v.

43 Samuel Rubio, «El P. Fray Antonio Soler: Vida y obra», en Monasterio de San Lorenzo el Real de El Escorial en el IV Centenario de su Fundación 1563-1963, El Escorial, Patrimonio Nacional, 1964, págs. 500 y 503. 
de Navidad. 2) Villancicos del Corpus Christi. 3) Villancicos de San Lorenzo. 4) Villancicos de San Jerónimo. Desde el punto de vista de la estructura formal, dichos villancicos se atienen a cuatro modelos estructurales: 1) Introducción - Estribillo - Coplas. 2) Introducción - Estribillo - Coplas - Seguidillas. 3) Introducción - Estribillo - Tonadilla - Coplas. 4) Introducción - Estribillo - Recitado - Aria - (Recitado) - Minué. La aportación fundamental de Soler consiste en haber enriquecido y ampliado las posibilidades expresivas del género del villancico, partiendo de modelos formales preestablecidos. El principio esencial en la construcción de sus villancicos es la creación de una gran forma compuesta de varias partes en las que se hace uso de diferentes recursos compositivos (fragmentos corales y solísticos, fragmentos instrumentales y vocales, técnica imitativa y homofónica, etcétera). Asimismo, cabe diferenciar dos tendencias estilísticas en los villancicos de Soler: por una parte aquellos villancicos que se interpretaban en las principales festividades religiosas del monasterio de El Escorial que corresponden al cuarto tipo formal (los denominados villancicos con cantata interpolada) y que presentan una mayor duración, una dotación vocal-instrumental más amplia, una armonía más elaborada, así como una mayor complejidad formal tanto en el plano literario como en el musical; predominan una escritura de tipo virtuosístico, concebida para el lucimiento del solista: se trata en definitiva de los villancicos que muestran una influencia emparentada con la estética italiana, la cual tuvo oportunidad de conocer Soler cuando se trasladaba a Madrid. Otro estilo ofrece por el contrario una estructura compositiva más sencilla. Son los villancicos de Navidad que no pertenecen al género de calenda, que se alejan de las formas italianas que predominaban en los villancicos anteriormente citados y que incluyen formas españolas de origen popular (tonadillas, seguidillas, coplas, etcétera). La sencillez de la armonía tiene su correspondencia con el contenido de estos villancicos, protagonizados por personajes pertenecientes a capas sociales modestas $^{44}$.

Un segundo apartado dentro del ámbito de la música vocal está protagonizado por las obras escénicas, concebidas para que sean representadas y cantadas por los estudiantes del seminario y colegio. Para valorar la música teatral del padre Soler hay que tener en cuenta a quién estaba destinada: se trata de una música simple sin mayor pretensión que la de entretener a los colegiales y seminaristas participantes en las loas, autos, comedias, etcétera, de Soler. El

44 Véase nuestra tesis doctoral El padre Antonio Soler y el cultivo del villancico de El Escorial, San Lorenzo de El Escorial, Ediciones Escurialenses, 1993 (versión alemana: Die Villancicos des padre Antonio Soler [1739-1783], Fráncfort, Peter Lang Verlag, 1994), así como nuestra edición de sus villancicos: Padre Antonio Soler: villancicos, 4 vols., Madrid, Sociedad Española de Musicología, 1992. 
libretista que predomina en las obras escénicas de Soler es Calderón de la Barca en aproximadamente un cincuenta por ciento ${ }^{45}$.

Gracias a la música instrumental, el padre Antonio Soler alcanza un puesto de primer orden en la música española. Independientemente de las sonatas para tecla, que se estudian en el apartado IV.2, destacan en este ámbito los Seis conciertos para dos órganos; se trata de un género compositivo que apenas fue abordado por los compositores españoles. El subtítulo de la obra (Para la diversión del serenísimo infante don Gabriel de Borbón) explica claramente cuál era el fin de los conciertos. El contexto instrumental de estas obras no es el del órgano litúrgico ni su ambiente es sacro, sino que están concebidas para el órgano de cámara, cuya técnica es pareja a la del clave. Los Seis conciertos para dos órganos reúnen características semejantes a las sonatas para clave y están imbuidos por una atmósfera mundana y galante que nada tiene que ver con el polifonismo que hasta entonces inundaba la música para órgano. Por último, hemos de citar en el campo instrumental los seis Quintetos para cuarteto de cuerda (violines primero y segundo, viola y violonchelo) más un instrumento de teclado obligado que puede ser el órgano o el clave, tal como se especifica en el título de la obra, que corresponden a la etapa de madurez de Soler. Fueron compuestos en 1776 y están titulados de la siguiente forma: «Para la Real Cámara del Serenísimo Sr. Infante D. Gabriel, compuesta y dedicada a su Alteza Real por el P. Fr. Antonio Soler». Su estructura formal es más variada que la ofrecida por los conciertos para dos órganos. Así, los allegrettos de los quintetos III y IV siguen la forma de la sonata bipartita, aunque sin la repetición de cada parte. Un tiempo que está presente en todos los quintetos es la danza a cargo del minuetto, la cual en el quinteto IV es «con variazioni», al igual que ocurre con los conciertos para dos órganos; se trata de catorce variaciones construidas sobre el bajo del tema, el cual se repite como un ostinato. Otros movimientos llevan los nombres de fuga, rondó, pastorile, cantabile, términos que indican el carácter del tiempo respectivo. Se trata de obras camerísticas que suponen la transición del periodo barroco de Bach y Haendel al clasicista de Haydn y Mozart. Constituyen una obra perteneciente a la plena madurez del autor y muestran influencias tanto de Scarlatti como de Boccherini, cuya música de cámara Soler conocía. El compositor trata los instrumentos respetando su respectivo carácter tímbrico y de articulación, dentro del espíritu del estilo clasicista y lejos ya del barroco ${ }^{46}$.

45 Véase al respecto José Sierra, «Música del P. Antonio Soler para obras de Calderón», Revista de Musicología, vol. IV (1981), págs. 137-158.

46 Antoni Soler: Sis Quintets per a instruments d'arc, orgue o clave obligat, Barcelona, Biblioteca de la Diputación, ed. de Roberto Gerhard, 1933, pág. LXXII. 
La tercera contribución de Antonio Soler a la historia de la música se centra en la teoría musical. Su obra más relevante fue la Llave de la modulación y consta de 19 folios más 272 páginas. Se divide en dos partes: en la primera trata de la teoría de la modulación, además de una teoría de la creación artística y del significado de las reglas. Su exposición de los modos refleja la teoría bimodal, con la diferencia entre los modos mayor y menor basada en el intervalo de tercera sobre el primer grado. Las explicaciones de la tonalidad le dan pie para establecer una teoría de la modulación que da título a su obra. Incorpora, asimismo, el análisis acústico de los intervalos y de la escala, citando entre otros autores a Boecio, si bien su conocimiento de la doctrina musical de este filósofo no debió de ser muy profundo. Uno de los aspectos más novedosos en el tratado de Soler viene dado por sus reflexiones sobre la creación artística y la teoría musical, reflexiones que creyó necesario exponer previamente, pues sin un conocimiento previo de ambas no es posible «hacer buenas y sonoras modulaciones ${ }^{47}$.

Tras la gran polémica suscitada por la misa Scala Aretina de Francisco Valls, como vimos anteriormente, la segunda gran polémica está protagonizada por la Llave de la modulación de Antonio Soler. El primer compositor que reaccionó en contra de la Llave fue el maestro de capilla de la catedral de Mondoñedo, Antonio Roel del Río, con una obra de dieciocho páginas titulada Reparos músicos precisos a la Llave de la modulación del P. Fr. Antonio Soler..., la cual data del 16 de mayo de 1764. Justifica Roel su réplica diciendo que «con nueva doctrina se opone [Soler] no sólo a muchas cosas que él [Roel] tiene que decir, bien fundadas para el arte, mas a algunas dichas ya e impresas ${ }^{48}$. Soler contestó a Roel con la Satisfacción a los reparos precisos hechos por don Antonio Roel a la Llave de la modulación por su autor, el padre Fr. Antonio Soler, maestro de capilla y organista del Escorial, impresa en forma de epístola en 1765. Soler contesta puntualmente a las objeciones de Roel, las cuales son en opinión del monje escurialense fruto de la incomprensión. La erudición de que hace gala Soler en la Satisfacción es más amplia que en la propia Llave, pues recurre a autores como Cerone, Zarlino, Ulloa, Morales, Palestrina, San Gregorio, San Jerónimo, Moreri, Kircher, Foliano, Gafurio, Ciruelo, Tosca, Nasarre, Lorente, Martini, Guido de Arezzo, Gaudencio, Valls, Joaquín Martínez, Boecio, Gesualdo, Scarlatti, Manalt, Brossard, etcétera. Cuando el padre Soler aclara a

47 Antonio Soler, Llave de la modulación y Antigüedades de la Música..., Madrid, Joachin Ibarra, pág. 79.

48 Antonio Roel del Río, Reparos músicos precisos a la Llave de la modulación del P. Fr. Antonio Soler, maestro de capilla en el real monasterio del Escorial, por don Antonio Roel del Río, maestro de capilla en la catedral de Mondoñedo, Madrid, Antonio Muñoz del Valle, 1764, pág. 1. 
Roel su concepto de «modulación de cajón», vuelve a ratificar su valiosa doctrina de la creación artística.

El segundo ataque a la Llave fue publicado el mismo año en que Soler publicó su Satisfacción y está protagonizado por el Diálogo crítico reflexivo entre Amphión y Orpheo sobre el estado en que se halla la música en España, dado a la luz del mundo por un espíritu del otro que oyó esta conversación. Por mano de su amigo D. Gregorio Díaz. Comienza el autor del Diálogo recriminando a Soler el arrogarse haber inventado la modulación; antes de que el padre Soler escribiera su tratado «ya se modulaba en España con más extensión, gusto y arte» ${ }^{49}$. Afirma, asimismo, que el arte musical no avanzó nada ni con la Llave ni con los Reparos de Roel. También argüía el autor del Diálogo que Soler se olvidaba de los maestros españoles, era injusto con Nasarre y había contestado con excesiva agresividad a Roel.

Para Francisco León Tello fue una pena que Soler perdiese el tiempo en la redacción de sus trabajos de defensa, ya que trataban en su mayor parte sobre la temática menos interesante de su obra y no añadieron nada novedoso. Habría sido deseable que hubiese llevado a efecto el proyecto anunciado en el capítulo del preludio de realizar un estudio semejante aplicado a otras formas musicales cultivadas en su tiempo o en el arte polifónico precedente ${ }^{50}$.

\section{IV.2. LAS SONATAS PARA TECLADO}

Es en las sonatas donde Soler alcanza un puesto de primer orden en la música española. ¿Para qué instrumento estaban escritas? Soler compuso sus sonatas sin distinguir con claridad el instrumento para el que estaban destinadas. Rubio soslayó este problema titulando su edición Sonatas para instrumentos de tecla; por su parte, Kastner las tituló Sonatas para instrumentos de teclado (piano, órgano, clave o clavicordio). La mayor parte están concebidas para el clave, unas pocas para el órgano y en algunas del último periodo parece que el compositor tuvo en cuenta las posibilidades del piano. La falta de diferencias estilísticas entre la música organística y la música para clave era algo habitual en el siglo anterior a Soler, mientras que Carl Philip Emanuel Bach ya distinguía entre música de clave y de piano.

El padre Antonio Soler se forma en la doble vía de la tradición española y con el genial Domenico Scarlatti. Numerosas obras de Soler acusan su origen en la música de danza, y en ellas la influencia de su maestro Scarlatti no oscurece

49 Citado en Rubio, Catálogo crítico, pág. 34.

50 Francisco León Tello, La teoría española de la música en los siglos XVII y XVIII, Madrid, Instituto Español de Musicología, 1974, pág. 244 y ss. 
la de sus otros mentores españoles, Cabanilles y José Elías. Además, Soler conoció la vanguardia de la música europea de Boccherini y Haydn a través de su relación con la corte en El Escorial.

Es necesario aclarar que el término sonata empleado por Soler no tiene relación con el significado que adquirirá durante el clasicismo. En la época de Scarlatti y Soler, el término sonata servía fundamentalmente para diferenciar la música instrumental de la puramente vocal, uso que mantuvo durante el barroco. La sonata, según esta concepción, tenía como fin la explotación de los recursos del instrumento respectivo, sobre todo los instrumentos de tecla, con una finalidad educativa. Por encima del carácter formal, es más destacable el carácter pedagógico de la sonata, tal como se concebía en aquella época: de hecho, en Gran Bretaña sonata equivalía a lección y ya Schulz llamó la atención sobre la utilidad pedagógica y el gran valor de entretenimiento que podían proporcionar estas obras ${ }^{51}$. Ya hemos visto anteriormente cómo Scarlatti había denominado sus treinta primeras sonatas no con este nombre sino con el de $E s$ sercizi. Los valores educativos y de entretenimiento hasta ahora analizados son perfectamente aplicables a las sonatas del padre Soler, ya que buena parte de ellas las compuso, al igual que tantas otras obras instrumentales, para las clases con su discípulo regio, el infante don Gabriel, y para su «diversión».

Los aspectos pedagógicos antes aludidos aparecen constantemente en las sonatas del padre Soler. Algunos ejemplos sirven para ilustrarlo: ejercicios de escalas tanto para la mano derecha como la izquierda (perceptible en la sonata R 36), escalas ornamentadas, escalas interrumpidas o escalas en intervalos (R 48); acordes repetidos (R 100) o desplegados (R 36); ejercicios de terceras y de sextas (una buena muestra de ambas aparece en la sonata $R 24$ ); octavas que son expuestas simultáneamente (R 48) o desglosadas (R 113), trémolos, etcétera.

Por otra parte, los bajos de Alberti fueron conocidos por Soler, al contrario de lo que ocurrió con Scarlatti: este tipo de acompañamiento indica un cambio del estilo galante al clásico y es visible sobre todo en las sonatas de varios movimientos, lo cual no quiere decir que desconociera este recurso anteriormente (R 40). Encontramos, asimismo, ejercicios a base de saltos interválicos, algunos de los cuales requieren un gran virtuosismo del intérprete.

Sobre la influencia de Scarlatti en Soler como compositor de sonatas se ha discutido mucho. En el pasado la mayor parte de los musicólogos proclamaban la dependencia del padre Soler con respecto a Scarlatti: así, por ejemplo,

51 William S. Newman, The Sonata in the Classic Era, Chapel Hill, University of North Carolina Press, 1969, págs. 19, 23 y sss. 
W. Georgii afirmaba que las sonatas de compositores españoles del XVIII parecían un calco de las de Scarlatti ${ }^{52}$. Gilbert Chase, por su parte, escribe que, «por su espíritu y su estructura, cada página de sus sonatas proclama a Soler discípulo de Scarlatti. El músico español no hace innovaciones en la construcción, satisfaciéndose con aceptar la forma simple de un solo movimiento tal como la cultivó Scarlatti» ${ }^{53}$. Uno de los primeros musicólogos que difiere de estas apreciaciones que presentan a Soler como una figura secundaria es Rafael Mitjana, quien, al referirse a las 27 sonatas publicadas en Londres, escribió lo siguiente:

Esta colección es suficiente para demostrar la abundancia y la originalidad del compositor, y digna de especial estudio por su novedad absoluta. Ellas nos descubren una poderosa personalidad artística digna de la mayor admiración. La valentía de espíritu del padre Soler y su profunda ciencia se revelan, sobre todo, en el empleo de las modulaciones, porque comprendiendo todos los recursos que presta el sistema temperado de los instrumentos de teclado, se adelanta a su época y anuncia una nueva esfera de acción en la música. Las sonatas del padre Soler preludian ya el romanticismo por su color y por su sentimiento ${ }^{54}$.

Samuel Rubio insiste en esta tesis al afirmar sobre la calidad musical de sus sonatas que «en este aspecto se halla en línea paralela con su colega contemporáneo - y tal vez su maestro- Domenico Scarlatti, tanto en su fecundidad como en su inspiración» ${ }^{55}$. Posteriormente, Rubio escribió en 1979 lo siguiente:

Pudo ser, en consecuencia, Soler discípulo de Scarlatti, simultáneamente, en el doble arte de teclear y de componer, o pudo serlo directamente en el primer aspecto y sólo de modo indirecto en el segundo, en el sentido de que el estudio de las obras del maestro como ejercicio para el aprendizaje del teclado le proporcionara el conocimiento puramente teórico de la forma musical de tales piezas, es decir, de la sonata. Esta hipótesis, que alguien puede juzgar descabellada, explicaría la para nosotros relativamente tardía producción sonatística o instrumental, por un lado; por otro, puede prestar un magnífico apoyo aclarativo a los que niegan o negamos la tan decantada influencia scarlattiana sobre Soler ${ }^{56}$.

52 Walter Georgin, Klaviermusik, Zúrich, Atlantis, 1950, pág. 76 y ss.

53 Gilbert Chase, La música de España, Buenos Aires, Librería Hachette, 1944, pág. 124.

54 Citado en Rubio, «El P. Fray Antonio Soler: Vida y obra», pág. 504.

55 Samuel Rubio, Antonio Soler: sonatas para instrumentos de tecla, vol. I, Madrid, Unión Musical Española, 1957, prólogo.

56 Samuel Rubio, Notas al programa del ciclo «Padre Antonio Soler (1729-1783)», Madrid, Fundación Juan March, 1979. 
Partiendo de la sonata bipartita monotemática, el padre Soler llega a crear un lenguaje instrumental propio que incluye la adaptación de temas y motivos populares. Las principales características de sus sonatas las resume Santiago Kastner al afirmar que el monje escurialense cultiva una traza muy personal en la estructura de periodos sumamente cortos y ensarta en fila grupos de motivos con sus respectivas repeticiones, lo que da lugar a una forma y aspecto melódico mucho más desmembrado, de aliento más corto, amén de urdidura menos orgánica y constante que los moldes y perfiles melódicos de Domenico Scarlatti. En lugar de la expansión lírica de la melodía italiana, Soler da prioridad a los motivos concisos y graciosos de elementos de las danzas españolas, lo que otorga a su música un cuño muy nacional y castizo. Concluye Kastner diciendo que, a pesar de los italianismos, el lenguaje musical de Soler es esencialmente español ${ }^{57}$.

El fraseo de las sonatas de un tiempo está construido a base de la repetición de breves motivos de uno o dos compases: las repeticiones triples de los motivos de uno o dos compases son típicas del estilo de Soler: La brevedad de los motivos y su constante repetición dan lugar a la inclusión de frecuentes cadencias, lo cual otorga una especificidad propia a las sonatas del padre Antonio Soler. Sin embargo, en las sonatas ternarias la repetición del motivo no es tan evidente, pues éste ofrece una mayor amplitud en las repeticiones. Dichas sonatas incorporan ya varios tiempos, uno de los cuales es el denominado Intento, en el que un tema se desarrolla en forma fugada, recurriendo el padre Soler a las imitaciones normales y por movimiento contrario, cánones, etcétera. Es en el intento donde se manifiesta con mayor claridad la influencia en Soler de los organistas del siglo XVII y XVIII, cuyo repertorio había estudiado en su etapa de estudiante en el monasterio de Montserrat. En algunas de las sonatas de la última etapa pueden observarse asimismo rasgos de lo que será la sonata del clasicismo vienés, concretamente la aparición de un segundo tema que contrasta con el principal. Por otra parte, es perceptible el uso de una amplia gama de recursos como el empleo de la mano izquierda al mismo nivel y con las mismas exigencias virtuosísticas que la mano derecha, cruce de manos de gran dificultad técnica, saltos interválicos, notas repetidas, trinos, fragmentos en terceras y sextas, aspectos todos ellos que otorgan a la música de tecla soleriana una gran riqueza y variedad estilísticas.

Un problema que plantean algunas de las sonatas de Soler es la falta de simetría entre la primera y segunda parte. Se ha planteado la posibilidad de descuidos del compositor o errores por parte del copista. Santiago Kastner, con

57 Santiago KASTNER, Antonio Soler: 2 + 2 Sonatas, Maguncia, Schott, 1956, prólogo. 
su maestría habitual, sostiene la tesis de que la exactitud no constituía el fin último en la construcción de dichas sonatas ni era «regla invulnerable» ${ }^{58}$. Con la asimetría, Soler intentó huir de un rígido plan constructivo con su consiguiente encasillamiento preestablecido.

Un aspecto peculiar en las sonatas del padre Antonio Soler viene dado por el uso que hace del folclore español. Rafael Mitjana fue uno de los primeros en señalar este hecho al destacar el empleo del ritmo de bolero en la sonata $\mathrm{R} 4$. El ritmo de la sonata $R 21$ en do sostenido menor recuerda a un polo, una forma de la seguidilla gitana de Andalucía. El ritmo de la seguidilla es asimismo perceptible en la sonata R 90 en fa sostenido menor ${ }^{59}$.

Las sonatas del padre Antonio Soler preludian por sus cualidades a Haydn y Mozart, autores que debió de ignorar, tesis en la que insiste Kastner cuando afirma que la música de Soler «roza cuerdas cuyas vibraciones parecen anunciar la venida de Mozart» ${ }^{60}$. En opinión del musicólogo norteamericano William S. Newman, los rasgos del estilo galante en las sonatas de Soler son más patentes que en las de Scarlatti ${ }^{61}$. Por último, Kastner escribe que «la variedad tonal, las modulaciones y toda la construcción armónica y hasta la construcción de los periodos musicales con su intensidad y función tanto armónica como tonal y rítmica alcanzan bajo las manos del padre Soler una perfección que verdaderamente lo coloca entre los primeros maestros de su tiempo. Ofrece su arte un aspecto de completa maestría, de absoluto dominio musical» ${ }^{62}$.

58 Citado en Santiago KaStner, Antonio Soler: III Concierto para dos instrumentos de tecla, Barcelona, Instituto Español de Musicología, 1952, prólogo.

59 Rafael Mitjana, «Histoire de la musique. Espagne -Portugal», en Encyclopédie de la Musique, vol. I, París, Delagrave, 1920, pág. 2.183.

60 Kastner, 2+2 Sonatas, prólogo.

61 Newman, op. cit., pág. 283.

62 Santiago KaStner, Contribución al estudio de la música española y portuguesa, Lisboa, Ithaca, 1941, pág. 296. 